\title{
ANTIK ÇAĞ'IN OPUS SPICATUM ZEMIN DÖŞEMELERi
}

\author{
Opus Spicatum Floor Pavements of Antique Age
}

Esra SAYIN*

\section{öz}

Zemin döşemeleri, en eski uygarlıklardan günümüze kadar, ihtiyaçlar ve mimari mekânlara estetik değerler katma amacı ile daima var olmuştur. Hem estetik kaygılar hem de kullanım avantajları gözetilerek mimari mekânlarda uygulanan döşemelerin pek çok farklı tekniği vardır. Bu çalışmada, özellikle Geç Antik Çağ'da popülerliği artan opus spicatum döşemelerinin teknik ve işlevsel özellikleri ile tercih edildiği kullanım alanları değerlendirilmiştir. Çalışma kapsamında, opus spicatum döşemelerin teknik özellikleri incelenmiş ve uygulama ölçütleri bulundukları mekânlarla birlikte değerlendirilmiştir. Döşemelerin tercih edildiği mimari yapıların tipolojik ve kronolojik değerlendirmeleri ile işlevsel özellikleri ortaya çıkartılmaya çalışılmıştır. Böylece işlevsellik temelindeki mekân-döşeme ilişkisi tespit edilerek bugüne kadar gerçekleştirilen benzer çalışmalar ve arkeolojik bulgular çerçevesinde değerlendirilmiştir. Ayrıca, Anadolu ve Anadolu dışındaki opus spicatum döşemelerinin de incelenmesi ile döşemenin kökeni ve gelişiminin yanı sıra Anadolu coğrafyasındaki önemi de ortaya çıkarılmıştır. Sonuç olarak, opus spicatum tekniğindeki zemin döşemelerinin teknik özelliklerinin, yapımında tercih edilen pişmiş toprak malzemenin hammadde özellikleri ile de bağlantılı olacak şekilde; yüksek mukavemet, dış etkenlere karşı dayanıklılık ve hijyen avantajı olduğu tespit edilmiştir.

Anahtar Sözcükler: opus spicatum, pişmiş toprak, zemin döşemesi, mekân, Antik Çağ.

\section{ABSTRACT}

Reach up to today from ancients, floor pavements have existed to fulfill the needs and add aesthetic value to the architecture. Floor pavements that are applied to the structures considering both aesthetic concerns and advantages of usage have various techniques. In this research, opus spicatum floor pavements technical and functional features that especially increase their popularity in the late antique age and the preferred fields of usage will be analyzed. Within this scope, the structural features of opus spicatum floor pavements are studied and the applicable standard

\footnotetext{
* Arş. Gör., İstanbul Gelişim Üniversitesi, Uygulamalı Bilimler Yüksekokulu, Kültür Varlıklarını Koruma ve Onarım Bölümü, İstanbul/Türkiye. E-mail: esayin@gelisim.edu.tr. ORCID ID: 00000002-8982-0042.
}

turnitin $\square$ This article was checked by Turnitin. 
is being considered within its setting place. It's also strived to uncover the typological and chronological evaluations of the architectures that applied floor pavements and their significant fictional features. Thus, a functional-based relationship between space and floor tiling has been detected and the floor tiling works and its archeological findings that cover until today have also been studied. Moreover, not only the origins of floor tiling and its development have been discovered by analyzing similar samples from Anatolia and out of Anatolia but also the location in the region of Anatolia has been revealed. As a result, it has been determined that the technical features of the floor coverings in the opus spicatum technique are high strength, resistance to external factors and hygiene advantages.

Keywords: opus spicatum, terra-cotta, floor pavements, place, Antique Age.

\section{Giriş}

Mozaik sanatı içinde yer alan zemin döşemeleri, ilk uygarlıklardan günümüze kadar, intiyaçlar ve mekânlara estetik değerler katma amacıyla mimari tasarımın bir parçası olmuştur. Mozaik sanatının ortaya çıkışı konusunda farklı teoriler yer almaktadır. Bu teorilerden biri MÖ 4000'lerde ilk kez Sümerler tarafından kil ile basit şekillendirmeler sonucu oluşturulan parçaların kerpiç duvarlara çakılmasıyla oluşturulmuş olan döşemelerdir (Dunbabin, 1999: 5). Bu teoriye göre mozaik uygulamasının en erken örneği, Sümer yerleşim alanı Uruk'ta bulunan Eanna Tapınağı'ndaki cephe üzerinde yer almaktadır (Res. 1; Lenzen, 1972: 124-125). Warka Tapınağı olarak da bilinen Eanna Tapınağına ait cephe duvarında yer alan döşemede, kilden konik çiviler sivri noktaları çamur sıvaya batırılarak geometrik şekilde dekore edilmiş ve sağlamlaştırılmıştır (Fischer, 1971: 33). Daha sonra Mezopotamya yapılarının kerpiç duvarlarında da örneklerini gördüğümüz bu kilden yapılmış çiviler zaman içinde taş, tablet ve kemiklere göre daha gelişmiş bir yöntem haline gelmiş, mozaiğin temel birimi olan ve yüzeye yapıştırılan parçalardan farklı olarak alçı içine gömülerek uygulanmıştır (Fischer, 1971: 3334). Bu en erken örneklerden de anlaşılacağı üzere pişirilmeden kullanılmış dahi olsa kilin teknik özelliklerinin sağladığı avantajlar eski uygarlıklar tarafından fark edilip kullanılmıştır. Dolayısıyla ilk mozaik örnekleri ışığında insan hayatının her evresine büyük ölçüde giren yapı malzemelerinin en önemlilerinden birinin pişmiş toprak olduğu söylenebilir.

Bu bağlamda, en basit tanımıyla hammaddesi kil olan inorganik malzemelerin farklı tekniklerle şekillendirilip kurutulduktan sonra pişirilerek dayanıklıı̆ının arttırılması sonucu ortaya çıkan seramik ürünler, gözenekli 
yapıda olup kilin içindeki demir oranına göre toprağın farklı tonlarında renk alternatifi sunmakla beraber genelde kırmızı renklidir (Arcasoy, 1983: 2-3).

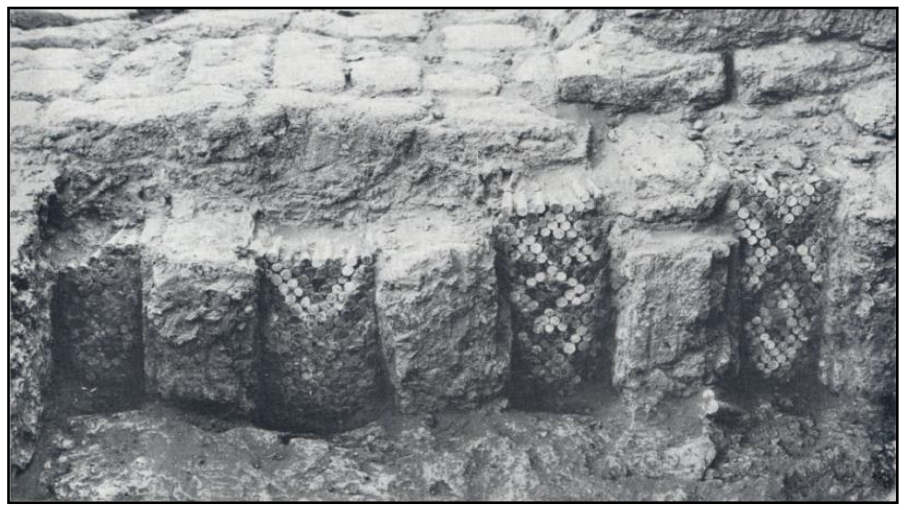

Resim 1. Eanna Tapınağı Cephe Duvarında Pişmiş Toprak Döşemeler (Lenzen, 1972: 129)

Gözenekli yapısı ve yüksek derecelerde fırınlanması sonucunda kazandığı dayanıklılığın mimari bağlamda avantaj sağlamasının yanı sıra estetik ve hijyenik özellikler de taşıması neticesinde tarihsel sürecin her evresinin vazgeçilmez öğesi olmuşlardır (Çobanlı ve Okur, 2006: 2). Bahsi geçen pişmiş toprak malzeme başlangıçta çanak, çömlek ve ziynet eşyası gibi tamamlayıcı malzeme niteliğinde iken gelişen teknoloji ile konut intiyacını karşılamaya yönelik mimari yapının bir parçası olarak da kullanılmıştır. Tamamlayıcı yapı malzemesi olarak kullanımının yanı sıra sahip olduğu teknik avantajlar nedeniyle antik dönem yapılarının zemin döşemelerinde de sıklıkla tercih edildiği görülmektedir. Bu şekilde hammaddesi pişmiş topraktan oluşan zemin döşemelerine ait bir örnek olarak opus spicatum tekniğindeki döşemeler gösterilebilir.

Genellikle dikdörtgen formlu tuğla parçaları ile tasarlanan bu zemin döşemesi literatürdeki adıyla "opus spicatum" olarak bilinmektedir. İsminin kökeni spica'dan [başak] gelmektedir ve esasında italya kökenli bir döşeme tekniği olarak karşımıza çıkmaktadır (Adam, 1999: 341). Spica isminin kökeninden de anlaşılacağı üzere dikdörtgen formlu pişmiş toprak parçalarının başak (balıksırtı) motifi oluşturacak şekilde yan yana dizilmesi ile oluşur (Res. 2; Soren, 1999: 379). Birbirine açılı şekilde döşenen tuğla parçalarının döşeme tasarımı ile başağı anımsatması sebebiyle doğa tarihi yazarı Plinius bu tip döşeme tekniği için "başak sırası" tanımını kullanmıştır (Plinius, 1971: XXXVI, 149). Opus spicatum tekniği ile yapılmış zemin döşemeleri genellikle MS I-II. yüzyıllarda Roma'da, özellikle Roma villalarında karşımıza çıkmak- 
tadır (Perring, 2002: 127). Ancak, bazı örneklerde pişmiş toprağın dayanıklılığı ve balıksırtı motifinin esnek taşıyıcı özelliğinden faydalanmak amacıyla duvarlarda kullanıldığı da görülmektedir (Adam, 1999: 32).

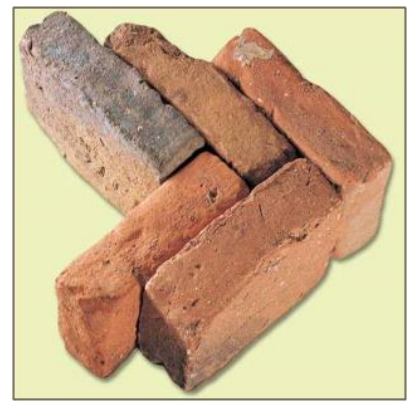

Resim 2. Opus Spicatum Balıksırtı (Başak) Tasarımı (URL-1)

\section{Opus Spicatum: Yapım Tekniği ve Malzeme}

Dış ortam koşullarına karşı mukavemeti ve hammaddesinin kolay elde edilebilir olması sebebiyle gerek duvar gerekse zemin döşemesi olarak kullanılan pişmiş toprak malzeme pek çok teknik özelliğe sahiptir. Bu özellikler; mekanik olarak yüksek mukavemet, yüksek basma kuvveti ile taşıyıcılık özelliği ve aşınmaya karşı dayanıklılı; fiziksel olarak, iletkenlik, ısıl denge ve özgül ağırlığın az olmasıdır (Toydemir, 2000: 279). Ayrıca su emme oranının oldukça yüksek olması, buzlanmaya dayanıklı oluşu ve açık alanlarda yağışla oluşan kayganlığı azaltması sebebiyle de genellikle dış mekân özelliği gösteren bahçe, avlu, yürüyüş yolları ya da kiler, havuz ve sarnıçlarda da sıklıkla tercih edilmiştir (Lugli, 1957: 1-49).

Pişmiş toprak malzemenin bahsi geçen tüm avantajları ve estetik değerleri göz önünde bulundurulduğunda antik dönem mimarlarının kentin en işlek caddeleri, dükkânlar, ev avluları ve hamam gibi sosyal kullanıma açık yapılarında bu teknikteki bir döşemeyi tercih etmesinin sebebi yeterince açıktır. Ayrıca aktif ticari ve sosyal hayatın getirisi olan hareketliliğe rağmen zamanla oluşacak aşınma aza indirgenecek ve böylelikle aşınmaya bağlı oluşacak tamirat en aza indirilecektir. Tüm bunların yanı sıra hava koşullarının tahribatı engellenecek, malzemenin su emiciliğinin yüksek oluşu nedeniyle ise ağır kış koşullarında oluşan don olaylarından etkilenmeyecektir. Ayrıca kolay temizlenebilir olması dükkânlarda hijyeni sağlayarak nem ve böceklenme gibi olumsuz durumlardan mekânları korumuş olacaktır. Tüm bu sebepler göz önünde bulundurulduğunda opus spicatum zemin döşemelerinin halkın sıklıkla kullandığı mekânlarda yer alması mimari yapılara ek- 
lenen döşemelerin sadece estetik kaygı gütmediğini, aynı zamanda işlevsel özellikler de taşıdığını göstermektedir.

Yoğun olarak kullanılan dış mekânlar için tüm bu avantajları sağlayan ve görünüm olarak yapıya farklı bir izlenim katan spicatum döşemelerin taban sağlamlaştırma sistemi ve yapım tekniği ise MÖ I. yüzyılda yaşamış olan Romalı mimar Vitruvius'un Mimarlık Üzerine 10 Kitap adlı eserinde anlattığı şekilde olmalıdır. Vitruvius'un önerisi önerisi şöyledir:

Mozaik taban hazırlanırken ilk önce molozlardan bir tabaka (statumen) hazırlanmalı, bunun üzerine iyi sıkılaştırılmış kaba agregalı bir harç (rudus), rudus üzerine ise terrakotta karışımlı bir harç (nucleus) yayılmalıdır, ardından tesseraların yapıştırılacağı ince harç tabakası hazırlanan bu katmanlar üzerine serilmelidir (1990: 151-152).

Hazırlanan zemin üzerine farklı motiflerle oluşturulan tasarımın ardından derz araları, tuğla parçalarının yüzeylerine taşmayacak şekilde ince bir harç ile doldurulmuş ve böylece sağlamlık arttırılmıştır:

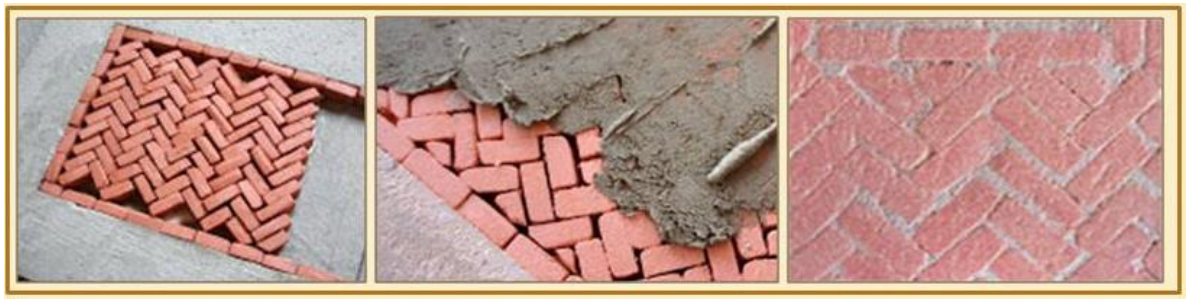

Resim 3. Opus Spicatum Döşemelerde Uygulama (URL-2)

\section{Opus Spicatum Zemin Döşemeleri ve Mekân iliş̧kisi}

Yaşam sürecinin her evresinde olduğu gibi antik dönemde de bir yapının başarılı sayılması, o yapının iç ve dış ortam koşullarına, plan ve detay tasarımlarına, yapıyı oluşturan malzemelerin özelliklerine bağlıdır. Dolayısıyla yapının mimari tasarımının ideal olması o yapının sağlam, kullanışlı ve estetik olması için yeterli değildir. Bu aşamada yapı malzemeleri ön plana çıkmaktadır. Bu husustaki en önemli nokta ise yapı malzemelerindeki maliyet, estetik ve işlevsellik gibi etkenler ile basınç dayanımı, kar, yağmur ve donma-çözülme gibi doğa etkilerine dayanıklılıktır. Özellikle dış mekânı olan yapılar yağmur, kar, güneş ışınları ve ısı değişimleri gibi doğa olaylarında iç mekânlara göre daha büyük oranda etkilenmektedir. Bu sebeple dış mekân özelliği gösteren yapılarda doğa unsurları göz önünde bulundurularak uygun malzeme seçimi ile daha kullanışlı mekânlar tasarlanmalıdır. Bu kullanışlılık kaygısı aynı zamanda estetik unsurlardan yoksun olmamalıdır. 
Mimarlığın en temel tanımını yapan Romalı mimar Vitruvius'un da mimarlık betiminde belirttiği gibi, yapılarda yararlılık ve sağlamlık öğelerini izleyen üçüncü temel öğe güzelliktir (Roth, 2000: 89).

Antik dönem yapılarında bahsi geçen estetik unsurlar denildiğinde akla ilk gelen öge mozaiklerdir. Zemin, duvar ve tavanlara uygulanan mozaikler, mekânların kimlik kazanmasında önemli bir rol üstlenerek yapı ile mekân arasında ara yüz işlevi görürler. Aynı zamanda mekânsal farklılaşmaların tanımlanmasına da yardımcı olurlar. Bu bağlamda antik dönem yapılaşmalarında mozaikler ve mimari yapılar arasında kuvvetli bir ilişki olduğundan bahsetmek kaçınılmazdır. Mekânların zeminlerini süsleyen mozaikler ise uygulanacak alanın büyüklüğüne ve şekline göre tasarlanmak zorundadır (Dunbabin, 1999: 304). Dönemin ekonomisini, kültürünü ve sosyal kimliğini de yansıtan bu mozaikler sahip oldukları bezeme repertuarı sayesinde ait oldukları mekânların işlevleri konusunda fikir sahibi olmamıza da yardımcı olmaktadırlar (Witts, 2000: 292). Bunun yanı sıra mozaik ustalarının bir diğer dikkat ettikleri nokta, dönemin modası ve kullanılan malzemenin teknik özellikleri ile sağlanacak avantajlardır. Antik dönem mozaiklerinde kullanılan malzemelerin arasında önemli bir yere sahip olan pişmiş toprak ilk olarak dayanıklılığı ve geçirgenlik özelliği ile dış mekânlarda teknik açıdan tercih edilirken, toplumun estetik ve sanat anlayışındaki değişim ve planlı kentleşmenin gelişmesiyle daha geniş iç mekânlarda da yer almıştır (Eren, 2012: 5).

Anadolu ve italya örneklerinde karşılaştığımız opus spicatum zemin döşemelerinin kamusal anlamda dış mekân özelliği gösteren ana cadde ve yine bu kamusal alana bağlı dükkân/işlik işlevli iç mekânlarda da tercih edildiği görülmektedir. Mozaik ustalarının su geçirmezlik ve dayanıklılık gibi teknik özellikleri nedeniyle tercih ettikleri bu malzeme dış mekânlara büyük avantajlar sağlamasının yanı sıra, parlak doku ve renklerden oluşmaları sebebiyle estetik görünüme de katkı sağlamaktadır. Kolay temizlenebilir olması ve rutubet oluşumunu engellemesi ise dükkân, işlik ve villalarda hijyenin ön planda tutulduğunun göstergesidir. Nitekim Roma villalarında da aynı teknikle yapılmış zemin döşemelerini yemek odaları, mutfaklar ve büyük salonlarda da görmekteyiz.

\section{Kökeni ve Gelişimi}

Anadolu'nun antik kentlerinde bugüne kadar açığa çıkartılan opus spicatum döşemeler hakkında kapsamlı bilimsel çalışmalar henüz yapılmamıştır. Yine de bugüne kadar yürütülen arkeolojik kazı çalışmalarının rapor- 
ları incelendiğinde farklı kentlerde çok sayıda örneğinin açığa çıkartıldığı görülmektedir. Bu doğrultuda, Kibyratis Bölgesi'ndeki Kibyra, Phrygia Bölgesi'ndeki Laodikeia ve Hierapolis, Lykia Bölgesi'ndeki Patara, Karia Bölgesi'ndeki Stratonikeia ve Pamphylia Bölgesi'nin sınırları içerisinde yer alan Perge'de yer alan farklı yapılarda ve alanlarda opus spicatum döşemelerin açığa çıkartıldığı görülmektedir:

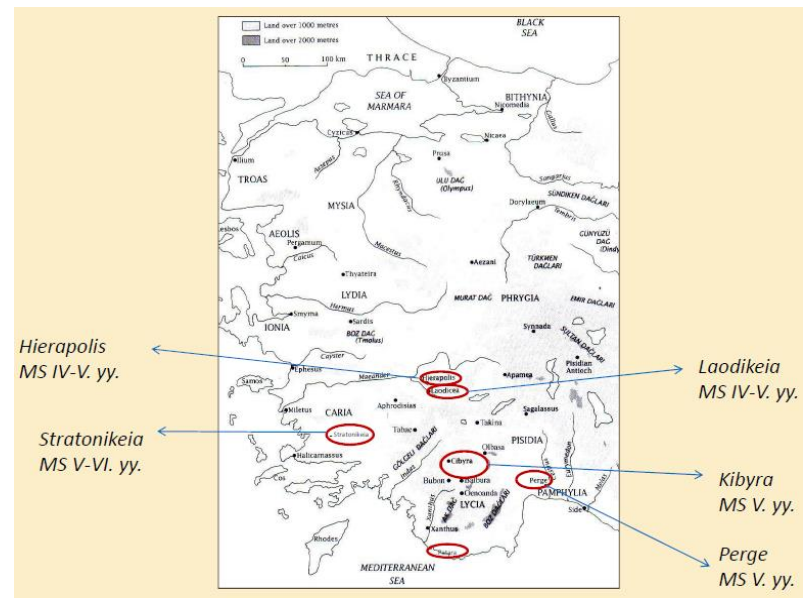

Resim 4. Opus Spicatum Zemin Döşemelerinin Anadolu'da Yayılımı

(Mitchell, 1993: I, 10)

Kibyra kentinde Agora'da kısmen açık alan özelliği gösteren stoada ve kentin geç dönem işlik ve dükkânları ile kentin bazilikal kilisesinde karşımıza çıkan örnekler çok çeşitli motifler ile tasarlanmıştır ve MS V. yüzyıla tarihlendirilmektedir (Sayın, 2015: 93).

Laodikeia'da kutsal mekânlarda ve iç mekân özelliği gösteren farklı konutlarda opus spicatum zemin döşemelerine rastlanılmaktadır (Şimşek, 2005: 426). Kentte yer alan ve genellikle geometrik motif tasarımına sahip opus spicatum döşemelerin yer aldığı yapıların MS II. yüzyılın ikinci yarısından MS VII. yüzyılın ilk yarısına kadar kullanıldığı tespit edilmiştir. Bu yapıların aktif olarak kullanıldığı dönemlerin ise MS IV-V. yüzyıllar olduğu ve olasılıkla döşemelerin bu tarih aralığında yapılmış olması intimali aktarılmaktadır (Şimşek, 2006: 464). Hierapolis'te ise sivil yerleşim alanlarında opus spicatum tekniği ile yapılmış döşemeler açığa çıkartılmıştır (Ruggiu ve Cottica, 2009: 153). Hierapolis'in geç dönem konut mimarisinde yer alan ve motif tasarımları oldukça sade olan bu döşemeler Kibyra ve Laodikeia örnekleri ile oldukça benzerdir. Döşemelerin yer aldığı sivil mimari ise MS IV-V. yüzyıla tarihlendirilmektedir (Ferrero, 1992: 318). 
Anadolu antik kentleri içinde opus spicatum zemin döşemelerine ev sahipliği yapan bir diğer kent ise Stratonikeia'dır. Stratonikeia'da da iç mekân özelliği gösteren yapılarda opus spicatum döşemelere rastlanılmıştır (Söğüt, 2012: 46). Bu mekânların farklı işlevlerle, Roma imparatorluk Dönemi'nden 20. yüzyıl ortalarına kadar uzun bir süre kullanıldığı bilinmektedir (Söğüt, 2012: 46). Kontekst buluntular ile birlikte değerlendirildiğinde döşemelerin MS V-VI. yüzyıllar içinde mekânlara eklendiği düşünülmektedir (Söğüt, 2012: 46). Perge'de ise MS II-V. yüzyıllar arasına tarihlenen sivil konutların bazı odalarında ve Güney Hamam'ın erken katmanlarında opus spicatum döşemelere rastlanılmıştır (Uğur, 2011: 68; Işıklıkaya-Laubscher, 2016: 171).

Anadolu' da bugüne kadar yapılmış kazılar sonucunda varlığını bildiğimiz bir diğer örnek ise Patara'da yer almaktadır. Kentin meclis binasının güneyinde konumlanan ve Prytaneion olduğu düşünülen yapı kompleksinin bazı bölümlerinde açığa çıkartılmıştır. Anadolu kentlerinde açığa çıkarılan opus spicatum tekniğindeki zemin döşemelerinin hem motif tasarımları hem de tercih edildikleri mekânlar açısından oldukça benzer olduğu ve kronolojik perspektifte değerlendirildiğinde ise neredeyse tümünün çağdaş oldukları görülmektedir. Anadolu dışındaki opus spicatum zemin döşemeleri incelendiğinde ise, Anadolu'da yer alan sınırlı sayıda örneğin aksine karşımıza pek çok benzer örneğin çıktığı görülmektedir. Bu örneklerin Anadolu opus spicatumlarına göre daha sade bir iş̧̧ilik ile yapıldığı ve motif tasarımlarının oldukça yalın olduğu görülmektedir.

Anadolu dışındaki opus soicatum döşemeler değerlendirildiğinde bunların en yoğun tercih edildiği yer olarak İtalya'nın en önemli yerleşimlerinden Ostia karşımıza çıkmaktadır. Ostia'da yer alan çok sayıdaki Roma villasında opus spicatum tekniği ile yapılmış zemin döşemeleriyle karşılaşmak mümkündür. Bu villalarda yer alan döşemelerin oldukça sade tasarlandığı ve çoğunun MS II. yüzyıla tarihlendirildiği görülmektedir. İtalya'da yer alan bir diğer örnek ise Via Appia üzerinde konumlanan Maxentius Villası'nda karşımıza çıkmaktadır. Döşemelerin yapım tarihleri tartışmalıdır; ancak büyük intimalle yapının Maxentius döneminden önceki evresine yani MS II. yüzyıla ait olduğu düşünülmektedir (Conlin, 2006/2007: 349).

Roma Tivoli'de İmparator Hadrian tarafından yaptırılan Adriana Villası'nın farklı mekânlarında da opus spicatum döşemeler yer almaktadır (Franceschini, 1991: 256-257). Buradaki döşemeler italya'daki diğer örneklerden farklı olarak sadece balıksırtı örgüsü ile tüm koridorları kaplamaktadır. Villa kompleksine ait diğer opus spicatum döşemeler ise Büyük Ha- 
mam'ın palaestrasında yer almaktadır. Olasılıkla pişmiş toprak malzemenin sağlamış olduğu kaymazlık ve su emicilik özelliğinden faydalanmak amacı ile hamamda tercih edilen bu opus spicatum döşemelerin neredeyse tamamı korunmuştur. Adriana Villası'nda yer alan döşemeler ve ait oldukları yapılar MS II. yüzyıla tarihlendirilmektedir (Franceschini, 1991: 256-257). Yine Roma sınırları içinde yer alan Via Gabina villa kompleksinde de opus spicatum döşemelere rastlanılmaktadır (MacDougall, 1987: 229). Döşemelerin tasarımları sadece balıksırtı örgü motiflerinden oluşmaktadır ve ait olduğu yapılar MS III. yüzyıla tarihlendirilmektedir (MacDougall, 1987: 227).

Bir diğer opus spicatum örneği ise italya'nın Anagni Kenti'nde yer alan Villa Magna yapı kompleksi içinde açığa çıkartılmıştır (Fentress, 2008: 1; Fentress, 2007: 5). Olasılıkla şarap üretimi ve fermantasyonu ile alakalı işliklerde yer alan döşemelerde mekânın fonksiyonuna dayalı, farklı bir tasarıma gidildiği görülmektedir (Fentress, 2008: 1). Pişmiş toprak malzemenin sahip olduğu mekanik özellikler nedeni ile zemininde opus spicatum döşeme tekniğinin tercih edildiği bu işlik MS I-II. yüzyıllara tarihlendirilmektedir (Fentress, 2007: 9). Opus spicatum döşemelerinin yer aldığı başka bir örnek ise Sardinya Adası'nın en önemli antik Roma yerleşim alanlarından biri olan Cagliari'deki Tigellio Villası'nda karşımıza çıkmaktadır. Burada yer alan döşemeler villa kompleksine ait Kuzey Hamam'da görülmektedir (Angiolillo, 1981: 60). Bezeme repertuarı açısından oldukça sade olan bu döşemeler italya örneklerinde olduğu gibi sadece balıksırtı örgü tekniği ile yapılmıştır. Villa kompleksi MS I. yüzyıldan MS IV-V. yüzyıla kadar kullanılmıştır (Angiolillo, 1981: 58). Döşemeler ise villanın ilk yapım tarihi olan MS I-II. yüzyıllara tarihlendirilmektedir (Angiolillo, 1981: 58).

İtalya dışında, Barcelona'nın Laietana Bölgesi'nde yer alan yapı kompleksleri incelendiğinde, bazı villaların döşemeleri için de opus spicatum tekniğinin tercih edildiği görülmektedir. İşlikler, depolar, mutfak ve konaklama odalarından oluşan tipik bir Roma villası niteliğinde olan bu alanlarda gerçekleştirilen kazı çalışmaları sonucunda ortaya çıkarılan opus spicatum döşemelerin bir kısmı bulunduğu mekânlardan sökülerek Musée d'histoire de Barcelone'da koruma altına alınmıştır (Altet, 1978: 14). MS II-III. yüzyıllara tarihlenen bu döşemelerin motif tasarımları ise oldukça sadedir. Galya Bölgesi'nde de karşımıza çıkan opus spicatum tekniğindeki döşemeler ise Fransa Suèvres Villası'nda açığa çıkartılmıştır. Döşemelerin korunabilen kısımları mekânlardan sökülerek Vendome Arkeoloji Müzesi'nde koruma altına alınmışlardır (Blanchard, 1991: 59). Buradaki döşemeler de bezeme repertuarı açısından italya örnekleri ile oldukça benzer olup sadece balıksırtı 
örgüsünden oluşmaktadır (Blanchard, 1991: 11). Yapılan değerlendirmeler sonucunda villa ve döşemeler MS IV-V. yüzyıllara tarihlendirilmiştir (Blanchard, 1991: 11).

Özetle, Anadolu dışında karşımıza çıkan çok sayıdaki örneğin içinden derlenmiş olan ve yukarıda detayları ile ele alınan opus spicatum tekniğindeki döşemeler, Anadolu'da karşımıza çıkan örneklerinin aksine daha basit bir motif tasarımlarına sahiptir. Bu döşemeler ait oldukları mekânların işlevleri doğrultusunda ufak farklılıklar dışında, genelde balıksırtı motifi ile tüm zemini halı gibi kaplamaktadır. MS I-II. yüzyıllarda özellikle Roma villalarında sıklıkla tercih edilen opus spicatum döşemeler, Anadolu örneklerinde de olduğu gibi özellikle işliklerde ve kısmen dış mekân özelliği gösteren stoalarda karşımıza çıkmaktadır. Ayrıca pişmiş toprak malzemenin sağlamış olduğu teknik özellikler sebebi ile hamamlarda ve villaların yemek odalarında da tercih sebebi oldukları görülmektedir. Anadolu dışındaki örnekler değerlendirildiğinde MS I. yüzyılla birlikte yaygın olarak kullanılmaya başlanan bu döşeme türünün Anadolu'da da olduğu gibi Geç Antik Çağ boyunca tercih edildiği görülmektedir.

\section{Sonuç}

Opus spicatum tekniğindeki zemin döşemelerinin teknik özelliklerinin, yapımında tercih edilen pişmiş toprak malzemenin hammadde özellikleri ile de bağlantılı olacak şekilde- yüksek mukavemet, dış etkenlere karşı dayanıklılık ve hijyen avantajına sahip olduğu söylenebilir. Bu sebeplerle antik dönem mimarisinin sivil konutları, açık alan özelliği gösteren yapı grupları, işlikleri ve hamamlarında sıklıkla tercih edilmişlerdir.

Köken gelişimi olarak incelendiğinde ise, Türkiye'de şu ana kadar yürütülen kazı çalışmaları ile açığa çıkarılan opus spicatum döşemelerin yoğunlukla Güneybatı Anadolu'da bulunduğu görülmektedir. Aynı zamanda neredeyse tüm örneklerin çağdaş olması, döşemelerin moda olup yaygınlaştığı bir dönem için kültür birlikteliğini yansıtmaktadır. Anadolu kentlerinde MS IV-VI. yüzyıllar arasında yaygın olarak görülen bu döşemelerin işlevsel olarak aynı özelliklerdeki mekânlarda tercih edildiğini de söylemek mümkündür. Anadolu dışındaki örneklerin daha erken dönemlere tarihlendirilmesi ise bu döşeme kültürünün Anadolu'ya daha geç tarihlerde geldiğini doğrulamaktadır.

Bezeme repertuvarında ise; Phrygia, Karia ve Lykia Bölgeleri'nde başta balıksırtı motifi olmak üzere genellikle geometrik motiflerin tekrar edilerek kullanıldığı, bazı motiflerdeki ufak değişiklikler dışında genel olarak benzer 
tasarımların tercih edildiği ifade edilebilir. Anadolu dışındaki örneklerde ise daha sade tasarımların tercih edildiği ve genellikle sadece balıksırtı motifi üzerine yoğunlaşan ustaların döşeme ile mekânların zeminlerini bir halı gibi kapladığı görülmektedir.

\section{Kaynakça}

Adam, Jean Pierre (1999). Roman Building: Materials and Techniques. New York: Routledge.

Altet, Xavier Barral (1978). Les Mosaïques Romaines et Médiévales de la Regio Laietana: Barcelone et ses Environs. Barcelona: Universidad de Barcelona, Instituto de Arqueología y Prehistoria.

Angiolillo, Simonetta (1981). Mosaici Antichi in Italia: Sardinia. Roma: Istituto Poligráfico e Zecca Dello Stato.

Arcasoy, Ateş (1983). Seramik Teknolojisi. İstanbul: Marmara Üniversitesi Yayınları.

Blanchard, Michéle (1991). Recueil Général des Mosaïques de la Gaule: II. Province de Lyonnaise. Paris: Centre National de la Recherche Scientifique.

Conlin, Diane A. (2006/2007). "The Villa of Maxentius on the Via Appia: Report on the 2005 Excavations". Memoirs of the American Academy in Rome, 51/52: 347-370.

Çobanlı, Zehra ve Okur, Ezgi (2006). "Seramik Yüzey-Mekân İlişkisi ve Anadolu Üniversitesi Güzel Sanatlar Fakültesi Seramik Bölümü Eğitim Programındaki Yeri”. Anadolu Sanat Dergisi, 7: 1-13.

Dunbabin, Katherine M. (1999). Mosaics of the Grek and Roman World. Cambridge: University Press.

Eren, Gülşen (2012). Kamusal Alanlarda Mozaik Çalışmalar. Ayasofya ve Sagrada Familia. Yüksek Lisans Tezi. Sakarya: Sakarya Üniversitesi Sosyal Bilimler Enstitüsü.

Fentress, Elizabeth (2007). "Excavation at Villa Magna 2006". The Journal of Fasti Online, Associazione Internazionale di Archeologia Classica, 1-22.

Fentress, Elizabeth (2008). 'Excavations at Villa Magna (Angni-FR) 2007”. The Journal of Fasti Online, Associazione Internazionale di Archeologia Classica, 1-18. 
Ferrero, Daria De Bernardi (1992). "1991 Yılı Hierapolis Arkeoloji Kurulunun Çalışma Raporu”. 14. Kazı Sonuçları Toplantısı, 2: 315-325.

Fischer, Peter (1971). Mosaics History and Technique. New York: Mc GrawHill Companies.

Franceschini, Marina (1991). Villa Adriana: Mosaici-Pavimenti-Edifici. Roma: L'erma di Bretschneider.

Işıklıkaya-Laubscher, Işıl (2016). "Perge Mozaik Atölyeleri ve Akdeniz Havzası Mozaik Ekolleri İçerisindeki Yeri”. Adalya, XIX: 169-227.

Lenzen, Heinrich J. (1972). "New Discoveries at WARKA in Southern Iraq". Archaeology, 17(2): 122-131.

Lugli, Giuseppe (1957). La Tecnica Edilizia Romana: Con Particolare Riguardo a Roma e Lazio I. Roma: Johnson Reprint.

Macdougall, Elisabeth B. (1987). Ancient Roman Villa Gardens. Washington: Dumbarton Oaks.

Mitchell, Stephen (1993). Anatolia: Land, Men, and Gods in Asia Minor-The Celts in Anatolia and the Impact of Roman Rule I. Michigan: Clarendon Press.

Perring, Dominic (2002). The Roman House in Britain. New York: Routledge.

Plinius (1971). Historia Naturalis: XXXVI. Trans. D. E. Eicholz. Harvard: Harvard University Press.

Roth, Leland M. (2000). Mimarlığın Öyküsü. Çev. Ergün Akça. İstanbul: Kabalcı Yayınevi.

Ruggiu, Annapaola Zaccaria and Cottica, Daniela (2009). "Hierapolis di Frigia fra Tarda Antichità ed XI Secolo: L'apporto Dello Studio Degli Spazi Domestici Nell'ınsula 104". Rivista di Archeologia, G. Bretschneider, 139-189.

Sayın, Esra (2015). Kibyra Antik Kenti'nden Opus Spicatum Döşemeler. Yüksek Lisans Tezi. Bursa: Uludağ Üniversitesi Sosyal Bilimler Enstitüsü.

Soren, David and Soren, Noelle (1999). A Roman Villa and a Late Roman Infant Cemetery: Excavation at Poggio Gramignano, Lugnano in Teverina. Roma: L'erma di Bretschneider.

Söğüt, Bilal (2012). "Stratonikeia 2011 Yılı Çalışmaları". 34. Kazı Sonuçları Toplantısı. 3: 45-59.

Şimşek, Celal (2005). "2004 Yılı Laodikeia Antik Kenti Kazısı”. 27. Kazı Sonuçları Toplantısı, 1: 419-434. 
Şimşek, Celal (2006). "2005 Yılı Laodikeia Kazı Çalışmaları”. 28. Kazı Sonuçları Toplantısı. 1: 455-478.

Toydemir, Nihat (2000). Yapı Elemanı Tasarımında Malzeme. İstanbul: Literatür Yayıncılık.

Uğur, Tülay (2011). Perge Antik Kentine Ait Mozaik Harçlarının Karakterizasyonu. Yüksek Lisans Tezi. İstanbul: İstanbul Üniversitesi Sosyal Bilimler Enstitüsü.

URL-1: "La época romana: Opus Spicatum". http://bertan.gipuzkoakultura.net/es/17/fr/4.php (Erişim: 23.01.2021).

URL-2: "Domus Project: Opus Spicatum". http://pietrasupietra.blogspot. com.tr/2010/01/indice-immaginicostruzione. htm (Erişim: 23.01.2021)

Vitruvius (1990). Mimarlık Üzerine On Kitap. Çev. Suna Güven. İstanbul: Şevki Vanlı Mimarlık Vakfı Yayınları.

Witts, Patricia (2000). "Mosaics and Room Function: The Evidence from Some Fourth Century Romano British Villas". Society for the Promotion of Roman Studies, 31: 291-324.

“COPE-Dergi Editörleri İçin Davranış Kuralları ve En İyi Uygulama ilkeleri” çerçevesinde aşağıdaki beyanlara yer verilmiştir:

Yazarın Notu: Bu makale, yazarın 2015 yılında Uludağ Üniversitesi, Sosyal Bilimler Enstitüsü tarafından kabul edilen "Kibyra Antik Kenti'nden Opus Spicatum Döşemeler" isimli yüksek lisans tezinden faydalanılarak üretilmiştir.

Teşekkür: Yazar, tez danışmanı Doç. Dr. Derya Şahin'e teşekkür eder.

Etik Kurul Belgesi: Bu çalışma için etik kurul belgesi gerekmemektedir.

Çıkar Çatışması Beyanı: Bu makalenin araştırması, yazarlığı veya yayınlanmasıyla ilgili olarak yazarın potansiyel bir çıkar çatışması yoktur.

The following statements are made in the framework of "COPE-Code of Conduct and Best Practices Guidelines for Journal Editors":

Author's Note: This article was produced from the author's master thesis titled "Opus spicatum pavements from ancient Kibyra city" accepted by Uludag University, Institute of Social Sciences in 2015.

Acknowledgment: The author thanks to her thesis advisor, Assoc. Prof. Dr. Derya Şahin.

Ethics Committee Approval: Ethics committee approval is not required for this study.

Declaration of Conflicting Interests: The author has no potential conflict of interest regarding research, authorship or publication of this article. 